\title{
Experimental Analysis of a Standalone Renewable Energy Based Hybrid System
}

\author{
Nuno Freire ${ }^{1}$, Eunice Ribeiro ${ }^{1}$, António J. Marques Cardoso ${ }^{1,2}$, and Chiara Boccaletti ${ }^{3}$ \\ ${ }^{1}$ Instituto de Telecomunicações, Department of Electrical and Computer Engineering, \\ University of Coimbra - Pole II, P - 3030-290 Coimbra, Portugal \\ nunofr@co.it.pt, eribeiro@co.it.pt \\ ${ }^{2}$ University of Beira Interior, Department of Electromechanical Engineering, Calçada Fonte do \\ Lumeiro, P - 6200-001 Covilhã, Portugal \\ ajmcardoso@ieee.org \\ ${ }^{3}$ Sapienza University of Rome, Department of Astronautics, Electrical and Energetic \\ Engineering, Via Eudossiana, 18, 00184 Rome, Italy \\ chiara.boccaletti@uniroma1.it
}

\begin{abstract}
This paper presents a small-scale prototype of a wind-photovoltaic hybrid system, having batteries as energy storage components. All devices are connected to a common dc-bus using appropriate power converters. The photovoltaic modules are connected through a dc-dc buck converter using Perturb and Observe Maximum Power Point Tracking control. The permanent magnet synchronous generator (wind generator) power interface is composed of a three-phase diode-bridge rectifier followed by a buck converter. A bidirectional buck-boost converter is applied to the batteries in order to control the dc-bus voltage, to which the load is directly connected. The whole hybrid system was built as a laboratory prototype, by using a dSPACE digital controller. Several experimental results are presented in order to analyze the system performance under both steady state operation and transients.
\end{abstract}

Keywords: Photovoltaic array, wind generator, battery, power converters.

\section{Introduction}

Renewable energy generators such as photovoltaic modules and wind generators have seen a great development during the latest decades and are currently considered mature and robust equipments. Their worst drawback is related to their dependence on climatic conditions resulting in an intermittent and unpredictable output power, which is not trustworthy for many applications. Therefore, their off-grid application always involves energy storage systems to match the power demand, overcoming the reduced generation by storing the surplus energy. To increase the reliability of such systems, different types of generators and energy storage components can be combined for an autonomous energy supply. Usually named as standalone power systems [1], their reduced need of maintenance and fuel-free operation makes them attractive for a great number of applications, especially in remote areas, where providing a grid connection 
can be highly expensive or even unfeasible [2]. Optimization of their sizing, simulation models and energy management are the greatest issues focused by research to improve the performance of these systems [3-5]. Although power electronic converters play a crucial role in conditioning the intermittent and variable power supplied by the generators, they are usually assumed as standard topologies for these applications and they have not been properly addressed in the literature yet [6].

Throughout this paper a standalone renewable energy based hybrid system is presented and thoroughly analyzed, focusing on the components that dominate its performance: power electronic converters. An experimental setup was designed, built and tested. It includes a photovoltaic (PV) array, a permanent magnet synchronous generator (PMSG), a battery pack, and a digital controller that allows for real-time control and monitoring of all power converters. The main goal is to supply a DC load with a constant voltage of $50 \mathrm{~V}$ reliably. The obtained results show that the chosen power converters and respective control methods are suitable for this kind of systems, making clear the major role of them for the achievement of the desired overall system performance.

\section{Contribution to Value Creation}

The present work is a step further for the creation of reliable, sustainable and environmental friendly ways of providing energy without a grid connection. This is particularly useful for applications in remote places, such as, for instance, radio base stations, where to provide a grid connection can be quite expensive and the conventional gensets might have unwanted additional maintenance costs [2]. Therefore, the study of power electronic converters for these systems contributes to the growth of economic value [2].

\section{Prototype Description}

The hybrid system (Fig. 1) is composed of a PV array and a wind conversion system based on a PMSG as the main sources, a battery pack for energy storage and backup, and a resistive load. The main goal is to supply the load demand, keeping its input voltage constant at $50 \mathrm{~V}$, using the intermittent energy provided by the generators, whose fluctuations are balanced by the batteries. All this components are connected through suitably chosen and designed dc-dc converters, which provide optimization and conditioning for each component output power.

The PV array is connected to the hybrid system through a buck DC-DC converter, as illustrated in Fig. 1. It controls the PV array output voltage, so that its maximum power point can be tracked using the Perturb and Observe algorithm, which is described in [7]. This solution was chosen for its simplicity, maturity and efficiency. The employed wind generator is a permanent magnet synchronous generator (PMSG) and its three-phase output voltage is rectified by a diode-bridge rectifier which is followed by a buck dc-dc converter similar to the one applied to the PV array, as shown in Fig. 1. The PMSG electromagnetic torque is controlled through the buck converter by controlling the value of the current $i_{P M S G}$. A buck-boost converter is responsible for keeping the load input voltage at $50 \mathrm{~V}\left(V_{D C}\right)$, through the appropriate 
control of the charging or discharging of the batteries. Therefore, the quantities required by the control system are: $i_{P M S G}, i_{P V}, V_{P V}$ and $V_{D C}$ (Fig. 1). The remaining quantities are only used for the analysis of the proposed hybrid system.

The batteries must be properly protected from overcharging and deep discharging. However, battery energy management issues are not the main concern of this paper and usually applied options such as dump loads and load shedding are not considered.

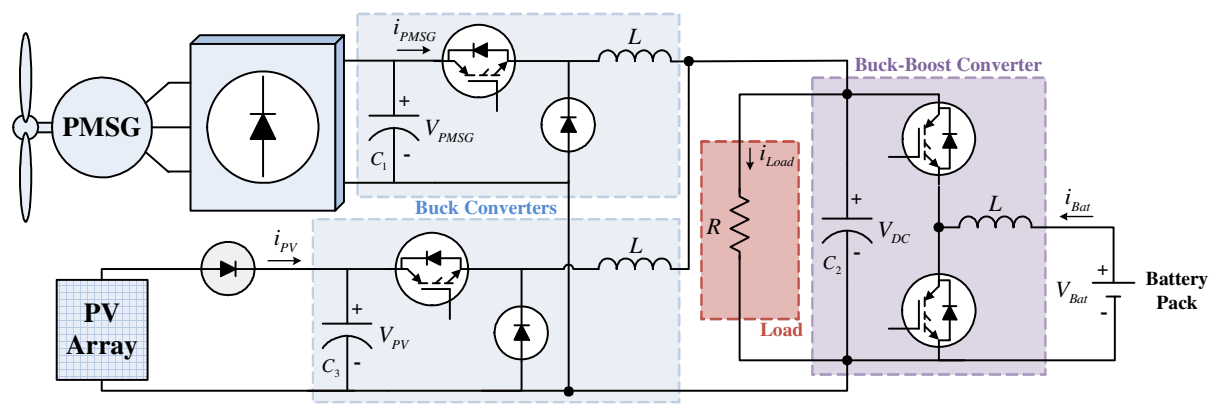

Fig. 1. Diagram of the standalone renewable energy based hybrid system

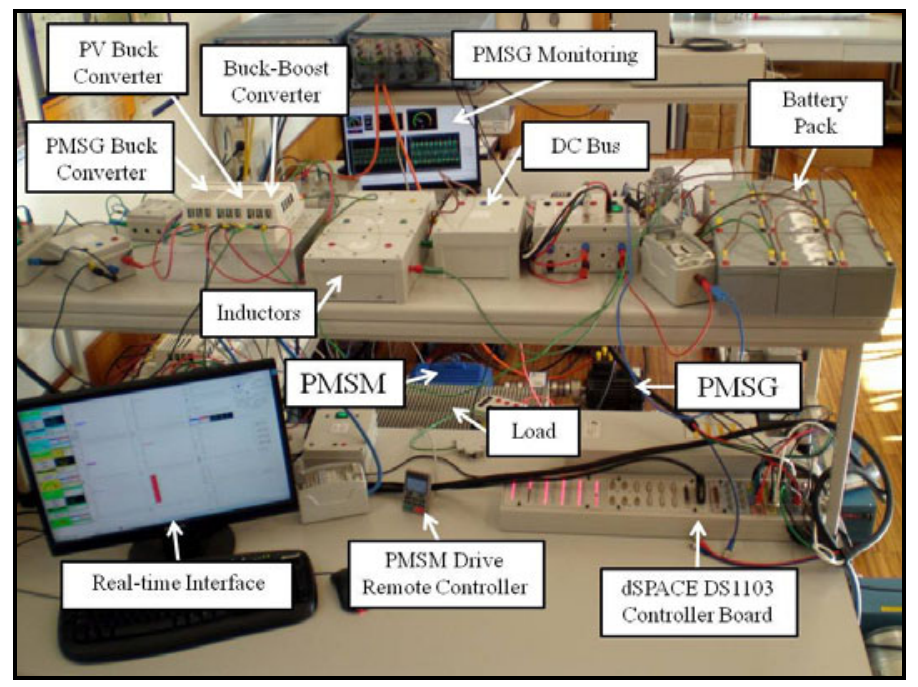

Fig. 2. General view of the experimental setup

The experimental setup is shown in Figs. 2 and 3. It includes a $2.2 \mathrm{~kW}$ PMSG coupled with a motor (PMSM) in a test bench (the latter emulates the spin of a wind turbine), a PV array composed of two series connected BP 4175 modules, a connection box for PV modules (PV laboratory interface - Fig. 3), a battery pack of $3 \times 312 \mathrm{~V} 12$ Ah lead acid batteries, Semikron IGBTs and diodes, eight voltage and current sensors, a dSPACE DS1103 digital controller and a variable resistive load. 
Tables 1, 2 and 3 present the PMSG, PV modules and converters parameters, respectively. As depicted in Fig. 2, all components have a modular structure, so that the system can be easily changed or redesigned.

The control strategies were implemented in the DS1103 digital controller board, using a sample time of $20 \mu \mathrm{s}$. The switching frequency imposed through the PWM techniques was $6 \mathrm{kHz}$ for the three dc-dc converters.

\section{Experimental Results}

Using the whole prototype setup previously described, several results were recorded and analyzed, using the dSPACE ControlDesk and Matlab/Simulink softwares.

Different operating conditions are considered in order to properly evaluate the system performance. On the one hand, under steady-state operation different battery operating modes were considered (charging/discharging). On the other hand, transient occurrences such as load and wind power generation changes were imposed.

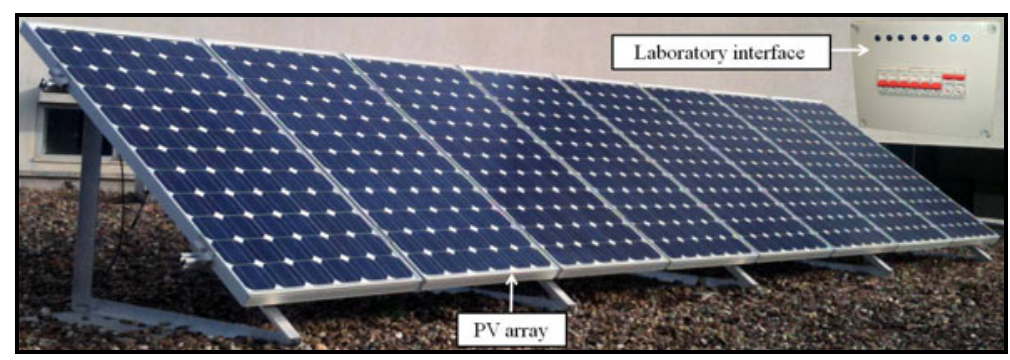

Fig. 3. Detail of the PV array and its laboratory interface

Table 1. PMSG parameters

\begin{tabular}{c|c}
\hline Power & $2.2 \mathrm{~kW}$ \\
\hline Speed & $1750 \mathrm{rpm}$ \\
\hline $\mathrm{V} \mathrm{ltage}$ & $316 \mathrm{~V}$ \\
\hline Current & $.2 \mathrm{~A}$ \\
\hline Number of pole pairs & 5 \\
\hline Armature resistance & $1.72 \Omega$ \\
\hline Magnet flux linkage & $0.244 \mathrm{~Wb}$ \\
\hline d-axis inductance & $20.5 \mathrm{mH}$ \\
\hline q-axis inductance & $20.5 \mathrm{mH}$ \\
\hline
\end{tabular}

Table 2. BP 4175 PV modules parameters

\begin{tabular}{c|c}
\hline Maximum power (Pmax) & $175 \mathrm{~W}$ \\
\hline Voltage at Pmax & $35 . \mathrm{V}$ \\
\hline Cur ent at Pmax & $494 \mathrm{~A}$ \\
\hline Short-circuit current & $5.4 \mathrm{~A}$ \\
\hline Open-circuit v ltage & $44 \mathrm{~V}$ \\
\hline
\end{tabular}

Table 3. System parameters

\begin{tabular}{c|c}
\hline $\mathrm{C}_{1}$ & $0.75 \mathrm{mF}$ \\
\hline $\mathrm{C}_{2}$ & $1.1 \mathrm{mF}$ \\
\hline $\mathrm{C}_{3}$ & $2.4 \mathrm{mF}$ \\
\hline $\mathrm{L}$ & $10 \mathrm{mH}$ \\
\hline $\mathrm{R}$ & $10-19.1 \Omega$ \\
\hline
\end{tabular}

The number of used PV modules was intentionally chosen so that the power provided by the PV array was not enough to supply the load. Therefore, by changing the PMSG load torque, it is possible to change the battery operation mode. 
Accordingly, for a reduced PMSG load torque, the battery will have to discharge to balance the load demand, whereas the battery will charge for a high PMSG load torque, since in this case the generated power (from both PV and PMSG generators) exceeds the load demand.

The PMSM drive controller is suitable for speed control. For all considered operating conditions a constant speed reference of $600 \mathrm{rpm}$ was imposed. As a consequence, the PMSG speed is constant and its load torque can be controlled through the reference value for $i_{P M S G}$.

During all conditions, the battery together with its power interface keeps the load voltage constant at $50 \mathrm{~V}$, as required, and balances the power production according to the load demand. The main goal of the analysis is to study the interactions between all the converters, their performance, and the system stability.

\subsection{Steady-State Operation}

Figs. 4 and 5 show all the acquired electrical measurements on the system for two distinct situations. As the PV array is not being emulated, its output cannot be changed, and its maximum output power (tracked by the converter control) remained almost constant at $118 \mathrm{~W}$. Changes in the power produced by the photovoltaic array occur very slowly. On the contrary, the emulation of the wind turbine permits to introduce changes at any time and to study how the system reacts.

In Fig. 4, the results depicted are the load, generator, PV and battery voltages, currents and powers for a PMSG load torque equivalent to $17 \%$ of the rated torque. The power produced by both generators is not enough to supply the load demand. Therefore, the battery discharges while keeping the load voltage at $50 \mathrm{~V}$ as required. In Fig. 5, the same results are depicted for a PMSG load torque equivalent to $33 \%$ of the rated torque. By increasing the torque, the generated power increases as well. Thus, the power produced by both generators exceeds the load demand. This surplus energy recharges the battery. Its voltage slightly rises while charging as expected.

In order to analyze the dc-dc converters performance under steady-state operation, efficiency and voltage peak-to-peak ripple values were chosen as evaluation parameters. The overall dc-dc converters efficiency can be obtained for the two considered operating conditions as follows:

$$
\begin{gathered}
\eta_{17 \% T_{n}}=\frac{P_{\text {Load }}}{P_{P M S G}+P_{P V}+P_{B a t}}=96.3 \% \\
\eta_{33 \% T_{n}}=\frac{P_{L o a d}-P_{B a t}}{P_{P M S G}+P_{P V}}=96.1 \%
\end{gathered}
$$

In the first case (Eq. 1), all the sources supply the load, in other words, all the power flows to the load. In the second case, the power generated by the renewable sources flows to the load and to the battery, which means that it supplies the load and charges the battery. It is worth noting that the minus sign in Eq. 2 results from the adopted convention for the battery current, which is negative when the battery is charging. Consequently, the converters efficiency level calculation depends on the battery operating mode.

In both operating conditions, the overall dc-dc converters efficiency values are high and similar, showing a quite good performance. 

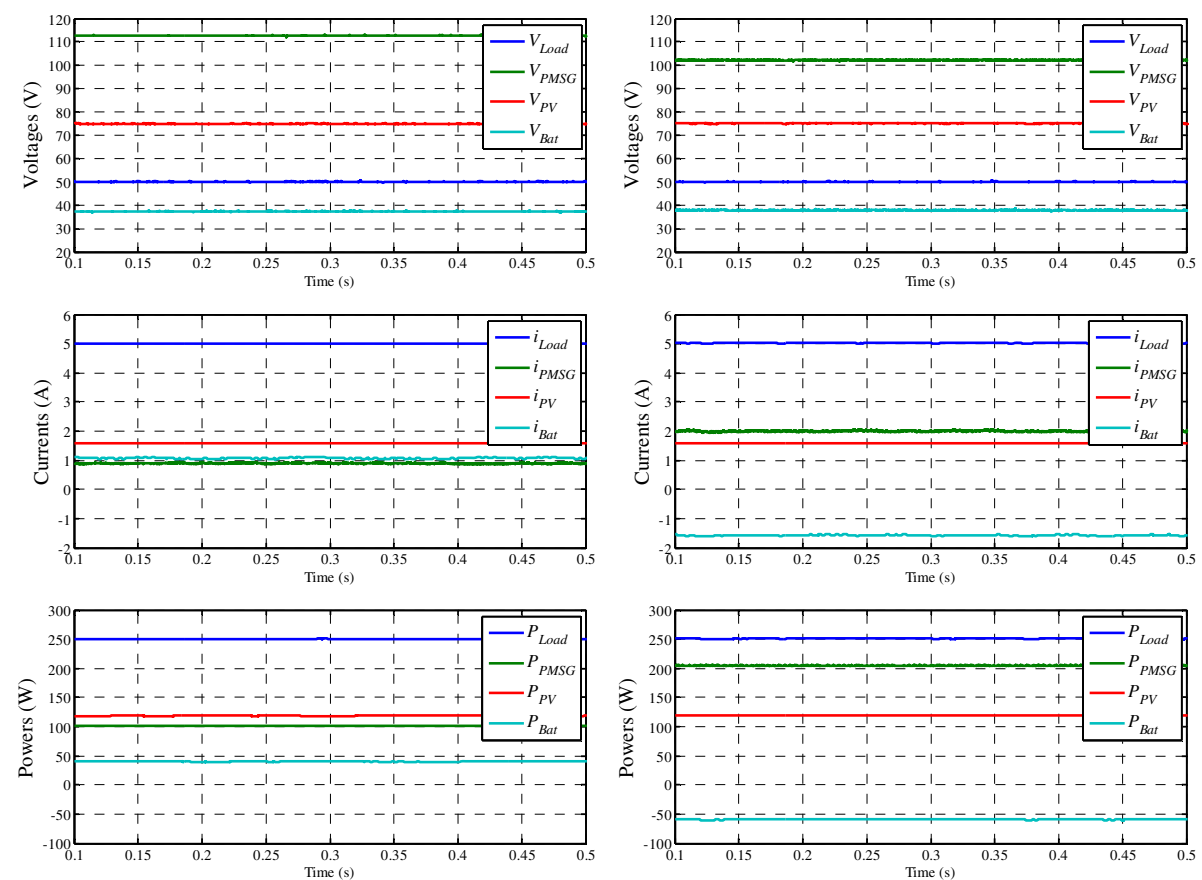

Fig. 4. Load, generator, PV and battery Fig. 5. Load, generator, PV and battery voltages, currents and powers for a PMSG voltages, currents and powers for a PMSG load load torque equivalent to $17 \%$ of the rated torque equivalent to $33 \%$ of the rated torque torque

The obtained voltage peak-to-peak ripple values were similar for the two considered operating conditions. They are shown in Table 4. The values are quite good for any DC power application, such as water pumping, radio base stations, among others.

Table 4. Voltage peak-to-peak ripple values

\begin{tabular}{|c|c|c|c|}
\hline & & \multicolumn{2}{|c|}{ Peak-to-peak ripple } \\
\hline & & Absolute Value & Relative Value \\
\hline \multirow{4}{*}{ Voltages } & $V_{D C}=V_{\text {Load }}$ & $0.5 \mathrm{~V}$ & $1 \%$ \\
\hline & $V_{P M S G}$ & $0.4 \mathrm{~V}$ & $0.4 \%$ \\
\hline & $V_{P V}$ & $0.4 \mathrm{~V}$ & $0.5 \%$ \\
\hline & $V_{B a t}$ & $0.3 \mathrm{~V}$ & $0.8 \%$ \\
\hline
\end{tabular}

\subsection{Transients}

The dynamic performance of the experimental setup for PMSG transients and varying load conditions are depicted in Figs. 6 and 7, respectively. 
Fig. 6 illustrates the electric parameters (voltage, current and power) of the generators, battery and load when such changes occur. At $0.13 \mathrm{~s}$ the PMSG load torque was increased from $17 \%$ to $33 \%$ of the rated torque, by increasing the reference of $i_{P M S G}$. As expected, the PMSG output voltage decreases and its current and generated power increase. This increase of the power injected into the dc-bus leads to an increase of $V_{d c}$, which is immediately counteracted by the buck-boost controller in order to keep $V_{d c}$ constant. However, a slight increase of $V_{d c}$ causes an increase of $V_{P V}$, resulting in a simultaneous reduction of the PV power. Following the stabilization of $V_{d c}$, the PV power returns to its previous value and the system reaches the steady-state. In spite of the battery change to the charging mode, the output voltage of the battery remains almost unaffected, showing its slow dynamic response. In addition, Fig. 6 shows that the system transient response is relatively fast.

A load transient can be seen in Fig. 7. At $0.4 \mathrm{~s}$ a load reduction from $234 \mathrm{~W}$ to 129 $\mathrm{W}$ was introduced, by controlling manually a variable load resistance. Once more, a transient is responsible for a momentary variation of $V_{d c}$, which is mainly reflected in the PV quantities. The PMSG outputs present a high immunity to this transient, remaining practically unchanged. Then, also for a load transient, the system presents a relatively fast dynamic response.
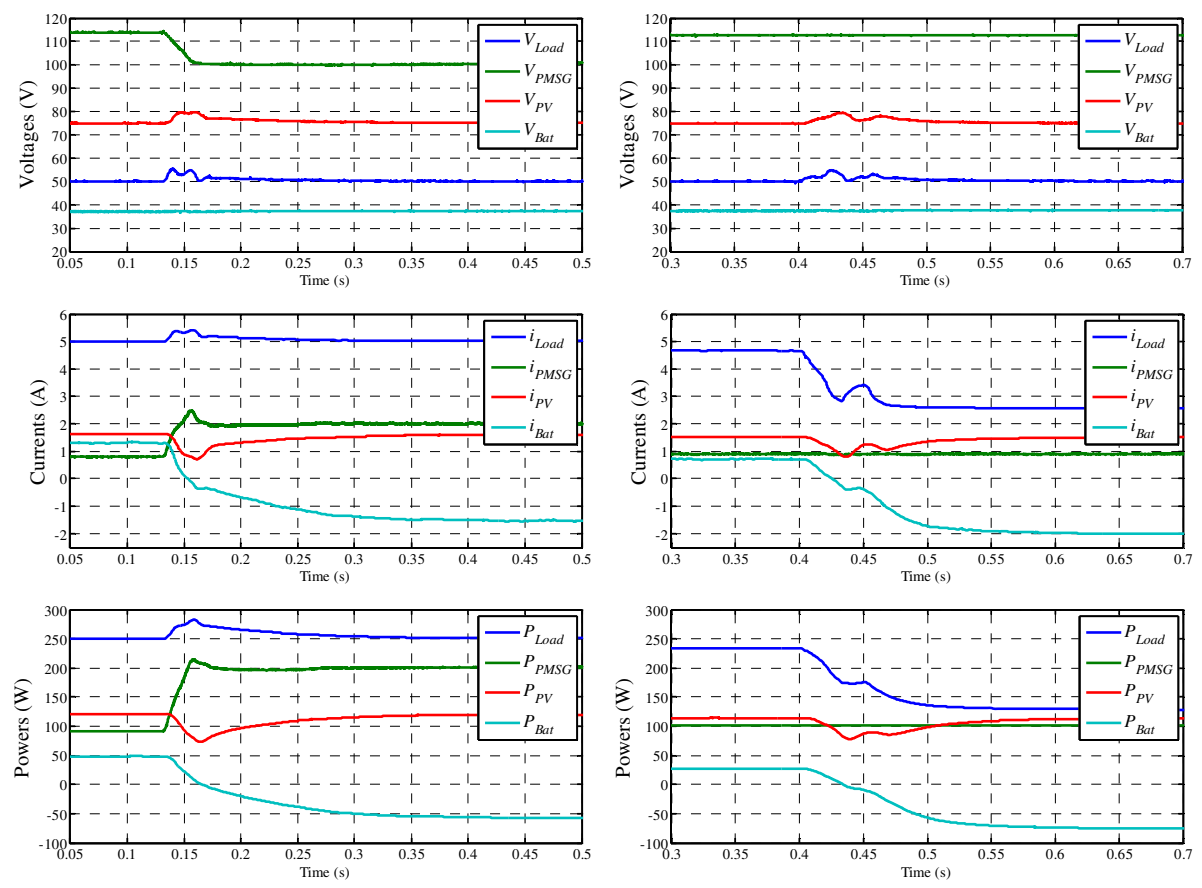

Fig. 6. Load, generator, PV and battery Fig. 7. Load, generator, PV and battery voltages, currents and powers during a PMSG voltages, currents and powers during a load transient change 


\section{Conclusion}

Taking advantage of the complementary nature of PV and wind generators, this paper proposes a hybrid system having these two as the main power sources. Although they are intermittent energy producers and dependent on the climatic conditions, the addition of a battery as an energy storage and backup balances any fluctuations. The addition of appropriate power converters and control strategies permitted to obtain an optimal and reliable operation of this system.

The performed experimental setup allowed to study the power converters employed in a hybrid system including a PV array, a PMSG and a pack of batteries. A complete description of this hybrid system was presented. The parameters of all components were given and the control of the power converters was explained. The obtained results have shown a great performance of the whole system and a good efficiency of the power converters. Different transients were introduced and the system rapidly adjusted to new steady states. The voltage of the common dc-bus was successfully kept constant under several operating conditions and the load demand was always assured by the hybrid system, confirming the effectiveness of the latter in supplying smoothed power for any standalone application.

Acknowledgments. This work was partly supported by Fundação para a Ciência e a Tecnologia (FCT) under Project No. SFRH/BD/47741/2008, Project No. PTDC/EEAEEL/114846/2009 and Project No. SFRH/BD/70868/2010.

\section{References}

1. Boccaletti, C., Fabbri, G., Santini, E.: Innovative Solutions for Stand Alone System Powering. In: 29th International Telecommunications Energy Conference, pp. 294-301 (2007)

2. Vazquez, M., Quiaones, C., Rascon, M.: Procedure to Select the Optimised Power Architecture for a Telecommunications Network of Remote Units. In: 21st International Telecommunications Energy Conference (1999)

3. Nelson, D.B., Nehrir, M.H., Wang, C.: Unit Sizing of Stand-Alone Hybrid Wind/PV/Fuel Cell Power Generation Systems. In: 2005 IEEE Power Engineering Society Meeting, vol. 3, pp. 2116-2122 (2005)

4. Shengtie, W., Zhiyuan, Q.: Coordinationation Control of Energy Management for Standalone Wind/PV Hybrid Systems. In: 4th IEEE Conference on Industrial Electronics and Applications, pp. 3240-3244 (2009)

5. Valenciaga, F., Puleston, P.F.: Supervisor Control for a Stand-Alone Hybrid Generation System Using Wind and Photovoltaic Energy. IEEE Transactions on Energy Conversion 20, 398-405 (2005)

6. Patsios, C., Antonakopoulos, M., Chaniotis, A., Kladas, A.: Control and Analysis of a Hybrid Renewable Energy-based Power System. In: 2010 XIX International Conference on Electrical Machines, pp. 1-6 (2010)

7. Hua, C., Lin, J., Shen, C.: Implementation of a DSP-Controlled Photovoltaic System with Peak Power Tracking. IEEE Transactions on Industrial Electronics 45, 99-107 (1998) 